Amir Mzé-Ahmed, Philippe Dagaut, Kamal Hadj-Ali, Guillaume Dayma, Thomas Kick, Julia Herbst, Trupti Kathrotia, Marina Braun-Unkhoff, Jürgen Herzler, Clemens Naumann, Uwe Riedel, The Oxidation of a Coal-to-Liquid Synthetic Jet Fuel: Experimental and Chemical Kinetic Modeling Study, Energy Fuels 26 (2012), 6070-6079.

\title{
dx.doi.org/10.1021/ef3009585
}

This document is the Accepted Manuscript version of a Published Work that appeared in final form in [Energy Fuels], copyright (C) American Chemical Society after peer review and technical editing by the publisher. To access the final edited and published work see

http://pubs.acs.org/articlesonrequest/AOR-eMWDuxw4K9ShuXRBBdZ2 


\section{The Oxidation of a Coal-to-Liquid Synthetic Jet Fuel: Experimental and Chemical}

\section{Kinetic Modeling Study}

Amir Mzé-Ahmed, Philippe Dagaut, Kamal Hadj-Ali, Guillaume Dayma

Centre National de la Recherche Scientifique, 1C, Avenue de la Recherche Scientifique 45071 Orléans Cedex 2 - France

Thomas Kick, Julia Herbst, Trupti Kathrotia, Marina Braun-Unkhoff, Jürgen Herzler, Clemens Naumann, Uwe Riedel

Institute of Combustion Technology, German Aerospace Center (DLR), Pfaffenwaldring 3840, 70569 Stuttgart, Germany

Correspondence: Philippe Dagaut

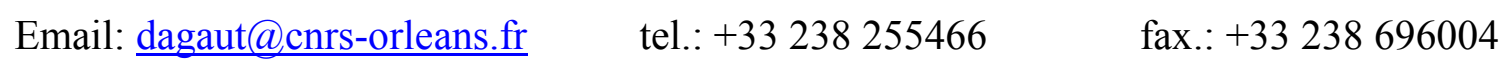

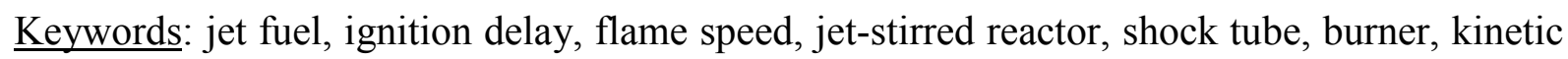
modeling

Shortened running title: CtL Jet Fuel Oxidation 
ABSTRACT: The kinetics of oxidation of a Coal-to-Liquid (CtL) Fully Synthetic Jet Fuel (FSJF) was studied using three complementary experiments operating over a wide range of conditions: a jet-stirred reactor ( $p=10$ bar), constant mean residence time of $1 \mathrm{~s}$, over the temperature range $770-1070 \mathrm{~K}$, and for equivalence ratios $\varphi=0.5,1.0$, and 2.0; a shock-tube ( $p \sim 16$ bar, temperature range between 900 and $1400 \mathrm{~K}, \varphi=0.5$ and $\varphi=1$ ), and a conical flame burner (preheat temperature $T_{0}=473 \mathrm{~K}$, and for two pressure regimes: $p=1$ bar for equivalence ratios ranging from 0.95 to 1.4 , and $p=3$ bar for equivalence ratios ranging from 0.95 to 1.3 ). Concentration profiles of reactants, stable intermediates, and final products in the jet-stirred reactor were obtained by probe sampling followed by on-line and off-line gas chromatography analyses and on-line Fourier Transformed Infra-Red spectrometry. Ignition delay times were determined behind reflected shock waves by measuring time-dependent $\mathrm{CH}^{*}$ emission at $431 \mathrm{~nm}$. Flame speeds were determined by applying the cone angle method. Comparison with corresponding results for Jet A-1 was performed showing similar combustion properties. The oxidation of the CtL-fuel under these conditions was modeled using a detailed kinetic reaction mechanism consisting of 8217 reactions and 2185 species and a 4-component surrogate fuel mixture ( $n$-decane, iso-octane, $n$-propylcyclohexane, and $n$ propylbenzene). A reasonable representation of the kinetics of oxidation of this FSJF was obtained. The model showed good agreement with concentration profiles measured in a jetstirred reactor at 10 bar over a range of temperatures $(550-1150 \mathrm{~K})$ and equivalence ratios (0.5-2). Good agreement between measured and predicted ignition delay times was found for the investigated fuel air mixtures, with significantly longer ignition delay times predicted. Also, the ignition behavior of the surrogate is mainly influenced by the $n$-alkane and not by the addition of iso-alkanes, naphthenes, and aromatics. In general, a reasonable agreement between predicted and measured burning velocity data exists, with larger deviations at higher pressure. No deviation is to be seen between burning velocity data for Jet A-1 and CtL, within the uncertainty range. Within the parameter range studied, the measured data of burning 
velocity and ignition delay time agree with data obtained earlier for petrol-derived kerosene. Our findings support the potential of the CtL/air mixture investigated to serve as an alternative aviation fuel. 


\section{INTRODUCTION}

Presently, the largest part of the energy used worldwide - electric power generation, heating, ground transportation, and aviation- is based on fossil fuels. In the last decade, alternative energy resources became increasingly important for several reasons, mainly to combat greenhouse emissions, but also to ensure security of supply and a lower increase of costs for energy by reducing fuel import dependency.

The aviation sector is also becoming part of the efforts finding alternatives to fuels stemming from fossil sources. In 2011, the European Commission has launched the European Advanced Biofuels Flight Path, an industry wide initiative to speed up the commercialization of aviation biofuels in Europe ${ }^{1}$. The "European Advanced Biofuels Flight Path" initiative is a roadmap with clear milestones to achieve an annual production of two million tons of sustainably produced biofuel for aviation by 2020 .

For these reasons, the commercial aviation sector is looking into alternative solutions, as blends or full substitution to kerosene. However, introducing new jet fuels in aeronautics is a great challenge, in particular with respect to the technical requirements: Aircraft needs are very strict and specific, with more severe constraints (e.g. freezing point, energy density, flash point, flammability limit, amount of aromatics... $)^{2-3}$ compared to any other transport means. Hence, any aviation fuel must be characterized and, with respect to its physical and chemical properties, to ensure a safe and reliable operation for the whole flight envelope. A further restriction is to proof that any newly developed alternative aviation fuel is fully compatible with today's airframe components and aero-engines, due to their long lifetime cycle.

Hence, it is of utmost importance to expand our knowledge on synthetic jet fuels not only with respect to the experimental characterization of the fuel properties but also with respect to modeling capabilities enabling predictive computational fluid dynamics simulations. To best optimize synthetic jet fuel mixture applications in practical combustors, the combustion characteristics of these fuels must be well understood. One of the most important fundamental 
combustion characteristics of any fuel, besides ignition delay time, is the laminar flame speed, as a mean for describing heat release. This knowledge enables avoiding conditions where selfignition or flashback may occur. These data must be known reliably over a wide range of temperatures, pressures, fuel compositions, and fuel-air ratios.

Till now, very limited data exist for the combustion of synthetic jet fuels. Kerosene is a complex mixture of numerous components, belonging to different chemical families; see e.g. 4-5. This is true also for fuels which may serve as alternatives (as blends or full substitution) to kerosene.

For small hydrocarbons (methane ${ }^{6}$, propene ${ }^{7}$ ), synthetic gas mixtures (methane/ $\mathrm{CO}^{8}$ and $\left.\mathrm{CO} / \mathrm{H}_{2}{ }^{9}\right)$, and higher hydrocarbons $\left(n\right.$-decane ${ }^{10}$, kerosene ${ }^{2}$ ), laminar flame speeds have been reported. These data are needed for validating sub-models incorporated in detailed chemical kinetic models describing the combustion of conventional and synthetic kerosene.

Flame speeds of Jet A-1 and other conventional fuels have been determined at atmospheric pressure with counter flow burner ${ }^{11}$ and stagnation flame burner ${ }^{12}$; for comparison, alternative fuels have been studied too, $\mathrm{S}-8$ and $\mathrm{GtL}{ }^{11}$, as well as palm oil methyl ester and mixtures with Diesel and Jet-A1 ${ }^{12}$. At ambient pressure also, flame speeds of components of jet fuel surrogates have been determined in counter-flow configuration, e.g. cyclohexane and alkylated cyclohexanes ${ }^{13}$, mixtures of $n$-dodecane with methylcyclohexane and toluene ${ }^{14}$. The influence of pressure on flame speed of Jet A-1 has been studied in an explosion vessel in the range from 1 to 4 bar $^{15}$.

To extend this database, the kinetics of oxidation of a CtL jet fuel was studied in a jetstirred reactor (JSR) at 10 bar, over a range of temperatures and equivalence ratios. Burning velocities of CtL-air mixtures were measured by applying the cone angle method ${ }^{5},{ }^{16}$. The experiments were performed at ambient and elevated pressure, for a preheat temperature of $473 \mathrm{~K}$ and for stoichiometric to rich mixtures. The measured burning velocities were compared with laminar flame speeds predicted by a detailed reaction model developed earlier 
17. We also studied the ignition characteristics of $\mathrm{CtL} /$ synthetic air mixtures diluted in nitrogen and of a CtL-surrogate blend ${ }^{18}$. The measurements were made at initial pressures of $\sim 16$ bar for two equivalence ratios and were compared with the predictions of the same detailed reaction model. The data obtained will be compared with those of Jet A-1 ${ }^{19}$. Thus, this work complements the latest developments on alternative jet fuel surrogate formulations and reaction models ${ }^{20-21}$.

\section{EXPERIMENTAL}

To understand the combustion of a fuel within an aero-turbine one has to take into account several aspects. Within the current work, we focus on the oxidation of the fuel and the formation of pollutants as well as on major combustion properties, i.e. burning velocity and ignition. These processes are taking place over a range of temperatures, pressures, and fuel-air ratios being considered among the most important parameters for operating an aero-turbine. For each of these parameters, a powerful experimental test rig was chosen: jet stirred reactor (oxidation, formation of pollutants), shock tube device (self-ignition of the fuel), and flame test rig (laminar flame speed). Each test rig was used for the investigation of several fuels, all of these investigations contributing to the development and optimization of a detailed reaction model. In all the experiments (JSR, shock-tube, and flame) we used the same fuel: a CtL Fischer-Tropsch synthetic jet fuel (FSJF) provided by Sasol $\left(\mathrm{C}_{11.06} \mathrm{H}_{21.6}, \mathrm{M}=154.32 \mathrm{~g} \mathrm{~mol}^{-1}\right.$, density $=815.7 \mathrm{~g} \mathrm{l}^{-1}$, composition in mass $\%$ determined via multidimensional gas chromatography analyses (9\% $n$-alkanes, 37\% iso-alkanes, $48.1 \%$ cyclo-alkanes, and $10.1 \%$ aromatics) and GC/MS analyses (36.3\% iso-alkanes, 5.7\% $n$-alkanes, $16.1 \%$ mononaphthenes, $28.3 \%$ di-/tri-naphthenes, 4\% mono-aromatics, 9.6\% naphthenoaromatics).

2.1 Jet stirred reactor. The experiments were performed in a JSR set-up ${ }^{22-24}$ used earlier. The reactor consists of a $39 \mathrm{~cm}^{3}$ sphere ( $4 \mathrm{~cm}$ diameter) made of fused-silica to minimize wall 
catalytic reactions. It is equipped with 4 nozzles of $1 \mathrm{~mm}$ i.d. for the admission of the gases which are achieving the stirring. A $1001 . \mathrm{h}^{-1}$ nitrogen flow was used to dilute the fuel. As before ${ }^{23-24}$, to minimize temperature gradients, before injection, all the gases were preheated at a temperature close to that in the JSR. A regulated heating wire of $\sim 1.5 \mathrm{~kW}$ (Thermocoax) maintained the reactor temperature at the selected working temperature. The reactants were mixed just before the entrance of the injectors. Nitrogen $\left(<50\right.$ ppm of $\mathrm{O}_{2} ;<1000 \mathrm{ppm}$ of Ar; $<5$ ppm of $\mathrm{H}_{2}$, all supplied by Air Liquide) was used as diluent and high purity oxygen (99.995\% pure, Air Liquide) was the oxidizer. All the gases were delivered using mass flow controllers (Brooks 5850TR and 5850E). A Shimadzu LC10 AD VP pump with on-line degasser (Shimadzu DGU-20 A3) was used to deliver the fuel to a temperature-controlled atomizer-vaporizer assembly maintained at $523 \mathrm{~K}$.

Thermal homogeneity along the vertical axis of the reactor was measured for each experiment using a $0.1 \mathrm{~mm} \mathrm{Pt}-\mathrm{Pt} / \mathrm{Rh} 10 \%$ thermocouple located inside a thin-wall silica tube. The reacting mixtures were probe sampled using a fused-silica low pressure sonic probe. The samples $(\sim 4-6 \mathrm{kPa})$ were taken at steady temperature and residence time. They were analyzed on-line by gas chromatography-mass spectrometry (GC-MS Saturn 2000, Varian) and Fourier Transformed Infra-Red spectrometry (FTIR), and off-line, after collection and storage in 11 Pyrex bulbs, by GC. Permanent gases and high vapor-pressure compounds were analyzed offline by GC whereas low vapor-pressure compounds were analyzed on-line by GC. The experiments were performed at steady state, at a constant mean residence time, the reactants continually flowing into the reactor while the temperature of the gases inside the reactor was varied stepwise. A high degree of dilution was used, reducing heat release, temperature gradients (gradients of $\sim 1 \mathrm{~K} . \mathrm{cm}^{-1}$ ) in the reactor, and preventing flame occurrence in the JSR. The operating pressure was manometrically measured at the exhaust using a high precision gage. GCs equipped with capillary columns (DB-5ms: 30m and 0.32mm i.d., DB-624: 60m and $0.32 \mathrm{~mm}$ i.d., Plot $\mathrm{Al}_{2} \mathrm{O}_{3} / \mathrm{KCl}: 50 \mathrm{~m}$ and $0.32 \mathrm{~mm}$ i.d., Carboplot-P7: $25 \mathrm{~m}$ and $0.53 \mathrm{~mm}$ 
i.d.), thermal conductivity detector, and flame ionization detector were used for quantifying stable species. A quadrupole mass spectrometer (GC/MS Varian 1200) operating in electron impact ionization mode $(70 \mathrm{eV})$ was used for compounds identifications. On-line FTIR analyses (Nicolet Magna 550; $2 \mathrm{~m}$ path length, $1 \mathrm{~cm}^{-1}$ resolution) were also performed allowing the quantification of $\mathrm{H}_{2} \mathrm{O}, \mathrm{CO}, \mathrm{CO}_{2}, \mathrm{CH}_{2} \mathrm{O}, \mathrm{CH}_{4}$, and $\mathrm{C}_{2} \mathrm{H}_{4}$. The fused-silica sampling probe was connected to a temperature controlled (413 K) gas cell via a $6.35 \mathrm{~mm}$ o.d. deactivated stainless steal heated line $(413 \mathrm{~K})$. Good repeatability of the measurements and good carbon balance $(100 \pm 15 \%)$ were obtained.

2.2 Shock tube. The experiments were carried out in a high pressure shock tube with an internal diameter of $46 \mathrm{~mm}$. It is divided by aluminium diaphragms into a driver section of $9.987 \mathrm{~m}$ and a driven section of $2.501 \mathrm{~m}$ in length. The driver section is heated to $393 \mathrm{~K}$. Helium was used as the main driver gas, and argon (Ar) was added to match the acoustic impedance of the driver gas. The exact mixture ratio was accomplished by two Bronkhorst ${ }^{\circledR}$ EL-FLOW $^{\circledR}$ mass flow controllers (accuracy $0.5 \%$ of the measurement value and $+0.1 \%$ of the maximum flow, respectively). These tailored conditions allow longer measurement times ${ }^{25}$. The driven section was heated to $433 \mathrm{~K}$ and pumped down to pressures below $10^{-4}$ mbar by a turbomolecular pump. Gas mixtures were prepared manometrically in a 51 stainless steel vessel heated to $553 \mathrm{~K}$ and evacuated using a separate turbo molecular pump to pressures < $10^{-4}$ mbar. For each experiment, a new mixture was prepared by injecting the fuel with a syringe into the evacuated vessel and mixing it with synthetic air $\left(80 / 20\right.$ vol $\left.\% \mathrm{~N}_{2} / \mathrm{O}_{2}\right)$ and additional nitrogen for dilution. After a mixing time of $30 \mathrm{~min}$ the fuel/air/ $\mathrm{N}_{2}$ mixture was filled into the shock tube. The compositions of the mixtures were controlled by gas chromatographic analyses which showed that no oxidation of the fuel occurred during the mixing time. The shock speed was measured over six $20 \mathrm{~cm}$ intervals using two times four piezo-electric pressure gauges. The temperature and pressure behind the reflected shock wave 
were computed from the measured incident shock speed and the speed attenuation using a one-dimensional shock model. The estimated uncertainty in reflected shock temperature is < $15 \mathrm{~K}$ in the temperature range of our measurements.

The ignition was observed by measuring pressure profiles with piezo-electric gauges $\left(\mathrm{PCB} \AA 112 \mathrm{~A} 22\right.$ and $\mathrm{Kistler}{ }^{\circledR}$ 603B) located $1 \mathrm{~cm}$ from the end flange. Also, the $\mathrm{CH}^{*}$ emission at $431 \mathrm{~nm}$ at the same position was selected by a narrow band pass filters (FWHM full width half maximum $=5 \mathrm{~nm}$ ) and measured with a photomultiplier. All ignition delay time values shown here were determined by measuring the time difference between the initiation of the system by the reflected shock wave and the occurrence of the $\mathrm{CH}^{*}$ maximum emission because this allows a good comparability to the simulations. The experimental setup allowed measurements of ignition delay times for observation times up to $8.0 \mathrm{~ms}$ depending on the temperature.

2.3 Burner. The burning velocities of vaporized liquid fuels were determined applying the cone angle method ${ }^{26}$, see Fig. 1. The concept of the existing burner system used previously for measuring the burning velocity of biogenic and synthetic gas mixtures ${ }^{6,27}$ was further engineered to use pre-vaporized liquid fuels in a newly constructed burner.

The burner test rig consisted of the burner housing with the flame holder, mass flow controllers (MFC, Bronkhorst) for regulating oxygen and nitrogen flows, the fuel metering pump (HPLC pump, Shimadzu, Prominence LC-20AD), the fuel evaporator ${ }^{28}$, and the homogenizing and cooling section. ${ }^{16,29}$

In order to avoid thermo-oxidative degradation, the fuel was deoxygenated by helium sparging. The fuel was vaporized at temperatures up to $600 \mathrm{~K}$ and mixed with the preheated nitrogen flow. As shown by Edwards and Atria ${ }^{30}$, thermal degradation and cracking of deoxygenated fuel is negligible at temperatures up to $600 \mathrm{~K}$ and maximum storage time of 15 
$\min ^{30}$. This was confirmed within the present work, as the prepared mixtures for measuring the ignition delay time were stable at least for 30 minutes according to GC analysis.

All parts containing pure vaporized fuel or nitrogen were heated to $570 \mathrm{~K}$. The ratio of nitrogen to oxygen flow was set to 79:21 (vol\%.) in order to mimic fuel-air mixtures. After combining fuel and nitrogen flow, the mixture was cooled down to $460 \mathrm{~K}$ before oxygen addition in order to avoid premature ignition. Then, the nitrogen-fuel and the oxygen flow were mixed and homogenized. The parts containing nitrogen/oxygen (air) fuel mixtures were heated to $460 \mathrm{~K}$. By controlling the temperature of the flame holder, the unburned air fuel mixture was preheated to the desired value.

Premixed conical shaped flames were stabilized above nozzle flame holders. In order to stabilize flames at variable fuel air ratios, nozzles with different diameters were used. Digital images of the flames were captured with a CCD camera (La Vision, Imager Pro Plus 2M, 1200x1600 Pixel). From these images, contours were extracted and cone angles calculated. Values of $S_{\mathrm{u}}$ were derived from the cone angle $\alpha$ and the velocity $v_{u}$ of the unburned gas based on the nozzle diameter and the volumetric flow rate (Fig. 1): $S_{\mathrm{u}}=v_{\mathrm{u}} \sin \alpha$. Conical flames could be stabilized at equivalence ratios from $\varphi \sim 0.95$ up to $\varphi=1.4$. At $\varphi<0.95$, no flames could be stabilized with a conical shape suitable for determining a value for the laminar flame speed. Increasing the equivalence ratio $\varphi \geq 1.4$, the flame got more and more unstable. Fluctuations of the flame cone led to increasing standard deviations of the measured values. At $\varphi>1.4$, measurements of burning velocities were impossible because the flame tip was opened, or the contour wrinkled ${ }^{29}$. The accuracy of the method of determining burning velocities, on one hand, is limited by deviations of the following factors: temperature and mass flow of unburned gas mixture; pressure; determination of cone angle and orifice area of the nozzles. The error of each of these values was $\sim 1$ to $1.5 \%$, resulting in an overall error of up to $5 \%$ with respect to the burning velocity. The maximum error of the equivalence ratio $\varphi$ ( $\mathrm{x}$-axis) of $\pm 2 \%$ is caused by deviations of the oxygen and fuel flows from desired values. 
Furthermore, on the other hand, a methodical error of the cone angle method exists given by flame strain and curvature ${ }^{31}$ and by a possible deviation of flow pattern from ideal plug flow ${ }^{32}$. In ref. ${ }^{33}$, flame speeds obtained by various methods were compared, including nozzle burners with conical flames and button shaped flames, closed vessel combustors, and counter flow burners. Depending on heat conductivity and diffusivities of the components of the gas mixtures, flame speeds derived from cone angle measurements may differ from those obtained by more exact stretch corrected measurements (see discussion in ${ }^{29}$ ).

The stretch rate $K\left(\mathrm{~s}^{-1}\right)$ of a flame is given by:

$$
K=1 / A \cdot d A / d t
$$

at which $A$ is the unit area of the flame front. In case of conical shaped premixed flames, $K$ can be formulated as:

$$
K=-v_{\mathrm{u}} \cdot \sin (2 \alpha) /(2 r)
$$

Markstein $^{34}$ gave a relation between measured stretched burning velocity $S u$ and the stretch rate $K$ :

$$
S_{\mathrm{u}}=S_{\mathrm{n}}-K \cdot L
$$

where

$$
\begin{aligned}
& L=M a \cdot \delta \\
& \delta=v / S_{\text {n. }} .
\end{aligned}
$$

Here, $S_{\mathrm{n}}$ is the unstretched burning velocity, $r$ the relevant flame radius, $L$ the Markstein length, $M a$ the Markstein number, $\delta$ thickness of flame front, and $v$ kinematic viscosity of unburned gas ${ }^{35}$. Vukadinovic et al. ${ }^{35}$ have determined Markstein numbers of Jet A-1/air mixtures and alternative jet fuel (GtL - Gas to liquid)/air mixtures by means of spherical expanding flames for equivalence ratios between $\varphi=0.7$ and $\varphi=1.4$. The Markstein numbers obtained are strongly depending on the equivalence ratio. Therefore, based on their Markstein numbers, the burning velocities measured in the present work are assumed to differ from 
stretched corrected values: up to $-10 \%$ in the fuel rich regime $(\varphi=1.4)$ and up to $+5 \%$ higher at stoichiometric conditions.

\section{MODELING}

The kinetic modeling was performed using the CHEMKIN II package ${ }^{36-37}$. We used the PSR computer code ${ }^{38}$ that computes species concentrations from the balance between the net rate of production of each species by chemical reactions and the difference between the input and output flow rates of species. Isothermal computations were performed. These rates were computed from the kinetic reaction mechanism and the rate constants of the reactions calculated at the experimental temperature, using the modified Arrhenius equation, $\mathrm{k}=\mathrm{A} \mathrm{T}^{\mathrm{b}}$ $\exp (-\mathrm{E} / \mathrm{RT})$. The rate constants for reverse reactions were computed from the corresponding

forward rate constants and the appropriate equilibrium constants, $\mathrm{K}_{c}=\mathrm{k}_{\mathrm{forward}} / \mathrm{k}_{\text {reverse }}$, calculated from thermochemistry ${ }^{17}$.

Concerning the shock tube experiments, kinetic modeling was performed using a Multiple Plug Flow Reactor (MPFR) code based on the CHEMKIN II package ${ }^{37,}{ }^{39}$. MPFR is an extension to SENKIN developed at DLR Stuttgart to take into account gas dynamic effects causing pressure and temperature variations, decoupled from the effects of heat release, combined with pressure relaxation effects along the shock propagation direction due to the shock tube's 'open end' configuration. Thus, the simulation assumes, for a time period of typically $250 \mu$ s or shorter depending on the heat release $(\Delta \mathrm{T} \leq 0.5 \%)$, a PFR with constant pressure conditions and takes into account the pressure increase by heat release within a PFRtime step along the shock propagation direction. The correction of the gas dynamic effects is based on the pressure profiles measured of mixtures with similar acoustic properties but without any heat release by chemical reactions. The temperature profiles are then calculated by applying adiabatic and isentropic conditions. These temperature profiles are used instead of constant initial temperatures $T_{5 \mathrm{~s}}$ for the simulation of experimental profiles with different 
chemical mechanisms. A typical experimental pressure profile, which shows no ignition during the measurement time, together with the calculated temperature profile is shown in Fig. 2. The pressure profile is identical to experiments with air as test gas; there is no heat release of the mixture during the measurement time.

Computer simulations of the laminar flame speeds were performed with PREMIX ${ }^{40}$, with thermal diffusion, assuming a free flame. Care was taken in the computations to reach the final solution (no significant evolution of laminar flame speed when the number of mesh points is increased); typically, more than 100 mesh points were computed.

Within the current work, we aim at developing a chemical kinetic reaction model for the combustion and ignition of a Coal to Liquid fuel (CtL) over a broad range of conditions (variable temperature, pressure, and equivalence ratio), on the basis of complementary experiments performed using the aforementioned experimental methods. A single model describing these aspects for different conditions is be desirable to reduce the need for timeand cost expensive experiments and to allow the possibility of numerical calculations taken into account the interaction between turbulence and chemical kinetic.

The kinetic reaction mechanism used here derives from previous modeling efforts for describing the oxidation of conventional and synthetic jet fuels with simple surrogates ${ }^{17}$. The surrogate mixture derives from chemical composition of the fuel (determined by GC analyses) for which representative hydrocarbons were selected in accordance with previous work on jet fuels combustion ${ }^{17}$. In the computations, the fuel was represented by a mixture of $n$-decane (CAS 124-18-5), iso-octane (2,2,4-trimethylpentane; CAS 540-84-1), n-propylcyclohexane (CAS 1678-92-8), and n-propylbenzene (CAS 103-65-1). To represent 1000 ppm of fuel, we used the following mole fractions: $n-\mathrm{C}_{10} \mathrm{H}_{22}: 0.000472$, iso- $\mathrm{C}_{8} \mathrm{H}_{18}: 0.000155, \quad n$ propylcyclohexane: $0.000445, n$-propylbenzene: 0.000122 . The model-fuel and the CtL fuel properties are compared in the following Table.

Table 1. Fuels properties 


\begin{tabular}{|l|l|l|}
\hline Property & CtL fuel & Model fuel \\
\hline Formula & $\mathrm{C}_{11.06} \mathrm{H}_{21.6}$ & $\mathrm{C}_{11.06} \mathrm{H}_{22.64} *$ \\
\hline $\mathrm{H} / \mathrm{C}$ & 1.953 & 2.047 \\
\hline Molar weight (g/mole) & 154.32 & $155.36^{*}$ \\
\hline Density (g/l) & 815.7 & 758 \\
\hline
\end{tabular}

* 1.1937 x C $_{9.27} \mathrm{H}_{19}$ since we used $1193.7 \mathrm{ppm}$ of model fuel to represent $1000 \mathrm{ppm}$ of CtL.

The same composition was used in all the computations presented here. The model fuel composition was chosen on the basis of multidimensional GC and GC/MS analyses (iso$36.3 \%$ alkanes -mainly $\mathrm{C}_{10}$ to $\mathrm{C}_{12}, 5.7 \%$ n-alkanes -mainly $\mathrm{C}_{9}$ to $\mathrm{C}_{11}, 16.1 \%$ mononaphthenes -mainly $C_{9}$ to $C_{13}, 28.3 \%$ di-/tri-naphthenes -mainly $C_{10}$ to $C_{15}, 4 \%$ monoaromatics -mainly $\mathrm{C}_{10}$ to $\mathrm{C}_{13}, 9.6 \%$ naphthenoaromatics, all in mass \%) and previous studies on SPK (synthetic paraffinic kerosene) and SPK/Jet A-1 oxidation ${ }^{17}$. Iso-octane is more branched than iso-alkanes present in the CtL fuel (mostly mono methyl-alkanes). Therefore, less $i s o$-octane is needed to represent the iso-alkane fraction of the fuel ${ }^{17}$. Also, carbon chains present on cyclic compounds increase their reactivity. To take this parameter into account, the fraction of $n$-alkanes must be increased significantly while reducing that of naphthenes. Therefore, the model fuels compares reasonably well with the CtL: paraffins $42 \%$ vs. $54 \%$ in the model (difference: $+29 \%$ in the model to account for side chains present in cyclic compounds); naphthenes: $49 \%$ vs. $36 \%$ in the model (difference: $-26 \%$ in the model to account for side chains present in cyclic compounds); aromatics $10 \%$ vs. $10 \%$ in the model. The proposed kinetic reaction mechanism consisting of 8217 reactions involving 2185 species is available from the authors. 


\section{RESULTS AND DISCUSSION}

4.1 Jet stirred reactor. The kinetic of oxidation of $1000 \mathrm{ppm}$ of $\mathrm{CtL}$ was studied at 10 bar in a JSR, over the temperature range 550 to $1150 \mathrm{~K}$, and at a mean residence time of $1 \mathrm{~s}$. The experiments were performed at three equivalence ratios $\varphi=0.5,1.0$, and 2.0 (Figs. 3-5). Under these conditions, the fuel reacted rapidly, yielding hydrocarbon intermediates (mostly methane and olefins) and oxygenates (mainly formaldehyde and $\mathrm{CO}$ ). A cool flame oxidation regime was observed in the temperature range 550-730 K. Mole fractions were measured for the reactants, main stable intermediates, and products: oxygen, hydrogen, water, carbon monoxide, carbon dioxide, formaldehyde, methane, ethane, ethylene, acetylene, propane, propene, 1-butene, 2-butenes, isobutene, 1,3-butadiene, isoprene, 1,3-pentadiene, benzene, and cyclohexene. A good repeatability of the results was observed. The accuracy of the mole fractions, derived from repeated experiments and repeated analyses, was typically $\pm 10 \%$ and better than $15 \%$ whereas the uncertainty on the experimental temperature was $\pm 5 \mathrm{~K}$. As can be seen from Table 2, the main products were $\mathrm{CO}_{2}, \mathrm{CO}, \mathrm{H}_{2} \mathrm{O}, \mathrm{CH}_{2} \mathrm{O}, \mathrm{CH}_{4}, \mathrm{C}_{2} \mathrm{H}_{4}$, and $\mathrm{C}_{3} \mathrm{H}_{6}$. Their mole fractions were larger under high-temperature oxidation regime than under coolflame conditions.

Table 2. Measured maximum mole fractions of products occurring during the oxidation of the stoichiometric mixture of CtL in a JSR at 10 bars.

\begin{tabular}{|l|l|l|}
\hline Measured & Maximum mole fraction at low & Maximum mole fraction at high \\
products & temperature & temperature \\
\hline $\mathrm{CO}_{2}$ & $9.7 \times 10^{-5}$ & $8.4 \times 10^{-3}$ \\
$\mathrm{CO}$ & $4.0 \times 10^{-4}$ & $6.7 \times 10^{-3}$ \\
$\mathrm{H}_{2} \mathrm{O}$ & $8.7 \times 10^{-4}$ & $8.1 \times 10^{-3}$ \\
$\mathrm{CH}_{2} \mathrm{O}$ & $1.2 \times 10^{-4}$ & $2.8 \times 10^{-4}$ \\
$\mathrm{H}_{2}$ & $9.5 \times 10^{-6}$ & $5.2 \times 10^{-4}$ \\
\hline
\end{tabular}




\begin{tabular}{|c|c|c|}
\hline $\mathrm{CH}_{4}$ & $1.0 \times 10^{-5}$ & $4.8 \times 10^{-4}$ \\
\hline $\mathrm{C}_{2} \mathrm{H}_{6}$ & $7.1 \times 10^{-8}$ & $3.1 \times 10^{-5}$ \\
\hline $\mathrm{C}_{2} \mathrm{H}_{4}$ & $1.3 \times 10^{-5}$ & $5.8 \times 10^{-4}$ \\
\hline $\mathrm{C}_{3} \mathrm{H}_{6}$ & $1.0 \times 10^{-5}$ & $1.7 \times 10^{-4}$ \\
\hline $1-\mathrm{C}_{4} \mathrm{H}_{8}$ & $1.9 \times 10^{-6}$ & $2.0 \times 10^{-5}$ \\
\hline $1-\mathrm{C}_{5} \mathrm{H}_{10}$ & $2.4 \times 10^{-6}$ & $9.3 \times 10^{-6}$ \\
\hline $1-\mathrm{C}_{6} \mathrm{H}_{12}$ & $8.7 \times 10^{-7}$ & $4.6 \times 10^{-6}$ \\
\hline $\mathrm{t}-2-\mathrm{C}_{4} \mathrm{H}_{8}$ & $9.6 \times 10^{-7}$ & $9.7 \times 10^{-6}$ \\
\hline$c i s-2-\mathrm{C}_{4} \mathrm{H}_{8}$ & $6.9 \times 10^{-7}$ & $6.7 \times 10^{-6}$ \\
\hline trans-2- $\mathrm{C}_{5} \mathrm{H}_{10}$ & $2.0 \times 10^{-7}$ & $2.4 \times 10^{-6}$ \\
\hline cis-2- $\mathrm{C}_{5} \mathrm{H}_{10}$ & $2.1 \times 10^{-6}$ & $9.3 \times 10^{-6}$ \\
\hline iso- $\mathrm{C}_{4} \mathrm{H}_{8}$ & $7.9 \times 10^{-6}$ & $4.5 \times 10^{-5}$ \\
\hline isoprene & $1.1 \times 10^{-6}$ & $1.1 \times 10^{-5}$ \\
\hline $\mathrm{C}_{2} \mathrm{H}_{2}$ & 0.0 & $3.6 \times 10^{-6}$ \\
\hline $\mathrm{C}_{4} \mathrm{H}_{6}$ & $5.9 \times 10^{-7}$ & $1.1 \times 10^{-5}$ \\
\hline $1,3-\mathrm{C}_{5} \mathrm{H}_{8}$ & $5.1 \times 10^{-7}$ & $3.6 \times 10^{-6}$ \\
\hline $\mathrm{C}_{6} \mathrm{H}_{6}$ & $6.8 \times 10^{-7}$ & $1.4 \times 10^{-6}$ \\
\hline cyclo- $\mathrm{C}_{5} \mathrm{H}_{8}$ & $7.5 \times 10^{-7}$ & $5.5 \times 10^{-6}$ \\
\hline cyclo $\mathrm{C}_{6} \mathrm{H}_{10}$ & $1.3 \times 10^{-7}$ & $4.3 \times 10^{-7}$ \\
\hline
\end{tabular}

The present data were compared to data obtained earlier for the oxidation of a typical Jet A-1. As can be seen from Fig. 6, Jet A-1 and CtL oxidize similarly. Nevertheless, it should be mentioned that under cool flame conditions $(550-750 \mathrm{~K})$ the oxidation of Jet A-1 is faster than $\mathrm{CtL}$, leading to larger formation of $\mathrm{H}_{2} \mathrm{O}, \mathrm{CH}_{2} \mathrm{O}$, and $\mathrm{CO}$. At higher temperature still, Jet A-1 tends to oxidize faster than CtL. Finally, as a result of lower iso-alkanes concentration in Jet A-1 (26 mass\% vs. 37 mass\% for CtL), isobutene is intermediately formed at much larger 
concentrations with CtL. As can be seen from Figs. 3-5 where the concentrations of the 13 most important products (see Table 2) are reported, the proposed model represents fairly well the data, although model improvements could be obtained under cool flame conditions. Such improvements should be achievable by using a more complex model fuel composition that would unfortunately increase the complexity of the kinetic reaction mechanism.

Reaction paths analyses indicated that the model-fuel components are mainly oxidized by metathesis with $\mathrm{OH}$ radicals,

n-decane:

1914. $\mathrm{n}-\mathrm{C}_{10} \mathrm{H}_{22}+\mathrm{OH} \rightleftharpoons \mathrm{H}_{2} \mathrm{O}+1-\mathrm{C}_{10} \mathrm{H}_{21} ;(R=-0.113)$

1915. $\mathrm{n}-\mathrm{C}_{10} \mathrm{H}_{22}+\mathrm{OH} \rightleftharpoons \mathrm{H}_{2} \mathrm{O}+2-\mathrm{C}_{10} \mathrm{H}_{21} ; \quad(R=-0.194)$

1916. $\mathrm{n}-\mathrm{C}_{10} \mathrm{H}_{22}+\mathrm{OH} \rightleftharpoons \mathrm{H}_{2} \mathrm{O}+3-\mathrm{C}_{10} \mathrm{H}_{21} ; \quad(R=-0.194)$

1917. $\mathrm{n}-\mathrm{C}_{10} \mathrm{H}_{22}+\mathrm{OH} \rightleftharpoons \mathrm{H}_{2} \mathrm{O}+4-\mathrm{C}_{10} \mathrm{H}_{21} ; \quad(R=-0.194)$

1918. $\mathrm{n}-\mathrm{C}_{10} \mathrm{H}_{22}+\mathrm{OH} \rightleftharpoons \mathrm{H}_{2} \mathrm{O}+5-\mathrm{C}_{10} \mathrm{H}_{21} ; \quad(R=-0.194)$

Iso-octane:

5502. $\mathrm{iC}_{8} \mathrm{H}_{18}+\mathrm{OH} \rightleftharpoons 2,2$,4-trimethyl-1-pentene $+\mathrm{H}_{2} \mathrm{O} ;(R=-0.382)$

5503. $\mathrm{iC}_{8} \mathrm{H}_{18}+\mathrm{OH} \rightleftharpoons 2,2,4$-trimethyl-3-pentene $+\mathrm{H}_{2} \mathrm{O} ;(R=-0.167)$

5504. $\mathrm{iC}_{8} \mathrm{H}_{18}+\mathrm{OH} \rightleftharpoons 2,4$,4-trimethyl-2-pentene $+\mathrm{H}_{2} \mathrm{O} ;(R=-0.128)$

5505. $\mathrm{iC}_{8} \mathrm{H}_{18}+\mathrm{OH} \rightleftharpoons 2,4$,4-trimethyl-1-pentene $+\mathrm{H}_{2} \mathrm{O} ;(R=-0.136)$

n-propylcyclohexane:

2992. $\mathrm{pch}+\mathrm{OH} \rightleftharpoons \mathrm{pchA}+\mathrm{H}_{2} \mathrm{O} ;(R=-0.109)$

2993. $\mathrm{pch}+\mathrm{OH} \rightleftharpoons \mathrm{pchB}+\mathrm{H}_{2} \mathrm{O} ;(R=-0.065)$

2994. $\mathrm{pch}+\mathrm{OH} \rightleftharpoons \mathrm{pchC}+\mathrm{H}_{2} \mathrm{O} ;(R=-0.065)$

2995. $\mathrm{pch}+\mathrm{OH} \rightleftharpoons \mathrm{pchD}+\mathrm{H}_{2} \mathrm{O} ;(R=-0.099)$ 
2996. $\mathrm{pch}+\mathrm{OH} \rightleftharpoons \mathrm{pchE}+\mathrm{H}_{2} \mathrm{O} ;(R=-0.197)$

2997. $\mathrm{pch}+\mathrm{OH} \rightleftharpoons \mathrm{pchF}+\mathrm{H}_{2} \mathrm{O} ;(R=-0.197)$

2998. $\mathrm{pch}+\mathrm{OH} \rightleftharpoons \mathrm{pchG}+\mathrm{H}_{2} \mathrm{O} ;(R=-0.099)$

n-propylbenzene:

2827. pbz $+\mathrm{OH} \rightleftharpoons$ pbzjA $+\mathrm{H}_{2} \mathrm{O} ;(R=-0.276)$

2828. pbz $+\mathrm{OH} \rightleftharpoons$ pbzjB $+\mathrm{H}_{2} \mathrm{O} ;(R=-0.225)$

2829. $\mathrm{pbz}+\mathrm{OH} \rightleftharpoons \mathrm{pbzjC}+\mathrm{H}_{2} \mathrm{O} ;(R=-0.188)$

yielding radicals that will further isomerize, decompose, and oxidize (normalized rate of production and consumption, $R$, were computed at $\varphi=1$ and 10 bar).

Among the main products, methane is mainly formed by reactions of methyl radicals with formaldehyde, $\mathrm{HO}_{2}$, and ethylene:

75. $\mathrm{CH}_{3}+\mathrm{HO}_{2} \rightleftharpoons \mathrm{CH}_{4}+\mathrm{O}_{2} ;(R=0.178)$

199. $\mathrm{CH}_{2} \mathrm{O}+\mathrm{CH}_{3} \rightleftharpoons \mathrm{HCO}+\mathrm{CH}_{4} ;(R=0.368)$

238. $\mathrm{C}_{2} \mathrm{H}_{4}+\mathrm{CH}_{3} \rightleftharpoons \mathrm{C}_{2} \mathrm{H}_{3}+\mathrm{CH}_{4} ;(R=0.105)$

Ethylene derives from the oxidation of ethyl radicals and beta-scissions:

217. $\mathrm{C}_{2} \mathrm{H}_{5}+\mathrm{HO}_{2} \rightleftharpoons \mathrm{C}_{2} \mathrm{H}_{4}+\mathrm{H}_{2} \mathrm{O}_{2} ;(R=0.029)$

231. $\mathrm{C}_{2} \mathrm{H}_{4}+\mathrm{HO}_{2} \rightleftharpoons \mathrm{C}_{2} \mathrm{H}_{4} \mathrm{O}_{2} \mathrm{H} ;(R=0.265)$

325. $\mathrm{C}_{2} \mathrm{H}_{5} \mathrm{O}_{2} \rightleftharpoons \mathrm{C}_{2} \mathrm{H}_{4}+\mathrm{HO}_{2} ;(R=0.175)$

463. $\mathrm{n}-\mathrm{C}_{3} \mathrm{H}_{7}(+\mathrm{M}) \rightleftharpoons \mathrm{C}_{2} \mathrm{H}_{4}+\mathrm{CH}_{3}(+\mathrm{M}) ;(R=0.073)$

Formaldehyde is mainly produced through the oxidation of vinyl and hydroxymethyl radicals and by decomposition of methoxy radicals:

2. $\mathrm{C}_{2} \mathrm{H}_{3}+\mathrm{O}_{2} \rightleftharpoons \mathrm{CH}_{2} \mathrm{O}+\mathrm{HCO} ;(R=0.39)$ 
161. $\mathrm{CH}_{2} \mathrm{OH}+\mathrm{O}_{2} \rightleftharpoons \mathrm{CH}_{2} \mathrm{O}+\mathrm{HO}_{2} ;(R=0.092)$

165. $\mathrm{CH}_{3} \mathrm{O}+\mathrm{M} \rightleftharpoons \mathrm{CH}_{2} \mathrm{O}+\mathrm{H}+\mathrm{M} ;(R=0.19)$

Iso-butene formation is mostly due to reactions pertaining to the iso-octane oxidation subscheme:

5395. $\mathrm{tC}_{4} \mathrm{H}_{9}+\mathrm{O}_{2} \rightleftharpoons \mathrm{iC}_{4} \mathrm{H}_{8}+\mathrm{HO}_{2} ;(R=0.416)$

5592. 2,4,4-trimethyl-2-pentene $\rightleftharpoons \mathrm{tC}_{4} \mathrm{H}_{9}+\mathrm{iC}_{4} \mathrm{H}_{8} ;(R=0.303)$

4.2 Shock tube. Ignition delay time data were measured for mixtures of Jet A-1 ${ }^{19}$, CtL and CtL surrogate in synthetic air $\left(20 \% \mathrm{O}_{2} / 80 \% \mathrm{~N}_{2}\right)$ for two equivalence ratios, $\varphi=0.5$ and $\varphi=1.0$, at pressures $p$ around 16 bar and for a dilution of 1:2 with nitrogen. The temperature range for those mixtures was between 900 and $1400 \mathrm{~K}$. The CtL surrogate consists of isooctane (13 mol\%), $n$-decane (39.5 mol\%), $n$-propylcyclohexane $(37.3 \mathrm{~mol} \%)$, and $n$ propylbenzene $(10.2 \mathrm{~mol} \%)$. The time period between the initiation of the reactive system by the reflected shock front and the observed $\mathrm{CH}^{*}$ maximum emission at $431 \mathrm{~nm}$ served as indicator for deriving ignition delay time data.

Then, calculations were carried out using the reaction model of the present work to enable a comparison between measured and predicted data applying the MPFR program extension to SENKIN ${ }^{37,39,41}$. In the simulations, the maximum of the calculated $\mathrm{CH}$ concentration was chosen as the indicator for the ignition. The results of the measurements compared with the reaction model predictions for the CtL and Jet A-1 surrogate ( $n$-decane (69 mol\%), $n$-propylcyclohexane (11 mol\%), and $n$-propylbenzene (20 mol\%) according to the work of Dagaut and Gail ${ }^{42}$ are shown in Figs. 7-8. The measured ignition delay times for CtL, the CtL surrogate, and Jet A-1 are almost identical. The simulations with the surrogates for kerosene and CtL differ also not very much, but give significantly longer ignition delay times compared to the experiments. 
In general, simulations with detailed chemical kinetic reaction models might exhibit quite large differences in the prediction of the ignition delay times due to different $n$-alkane sub models, because the ignition delay is dominated mainly by $n$-alkanes oxidation in these types of fuels. Therefore, simulations of the ignition delay time with $n$-decane as single compound were also performed; they agree very well with the values of the CtL surrogate (see Fig. 9). Experiments and simulation show that the addition of iso-alkanes, naphthenes, and aromatics in reasonable amounts has only a minor influence on the ignition delay time. Thus, the addition of further compounds to the surrogates, which are important to represent characteristic properties like derived cetane number, smoke point, aromatic content, sooting propensity and boiling behavior, do not significantly influence ignition. Basically, the combustion characteristics are well-predicted if the $n$-alkanes sub-mechanism is correct.

4.3 Burner. Figure 10 presents a comparison of measured burning velocities of CtL-air mixtures - to the best of our knowledge, reported for the first time - with predicted laminar flame speeds. The measurements were performed at ambient ( $p=0.96$ bar) pressure, for equivalence ratios $\varphi$ between about 0.95 and 1.4 , and at elevated ( $p=3$ bar) pressure, for equivalence ratios $\varphi$ between about 0.95 and 1.30). The error bars in Fig. 10 represent the experimental incertitude of the measured burning velocity data, without taken into account the influence of flame stretch, as discussed earlier.

The experimental data exhibit the major expected trends as a function of equivalence ratio and pressure. Also, the measured burning velocities are higher by up to about $15 \%$ within the range of equivalence ratio 1.0 to 1.2 , in agreement with Ji et al. ${ }^{11}$. However, the laminar conical shaped flames were stabilized over a limited range; practically no data points could be determined for fuel-lean mixtures. Therefore, the expected "bell-shape" curve was not observed. 
In general, the agreement between predicted and measured data is reasonable. For atmospheric pressure, the experimental values are over predicted in the fuel rich regime. For the equivalence range between 1.1 and 0.97 , the experimental values are under predicted, for both pressure conditions.

For comparison, data points for Jet A-1 measured at the same experimental test rig ${ }^{19}$ are also given in Fig. 10 (see diamonds), together with data gathered from the literature (circles: Chong and Hochgreb ${ }^{12}$; squares: Vukadinovic et al. ${ }^{35}$ ). No deviation is to be seen between data points for Jet A-1 and CtL, within the uncertainty range, measured at the same experimental test rig. Please note the range of the experimentally derived burning velocity data gathered from three different groups, each of them applying a different method reflecting the fact that a single Jet A-1 is not existing.

Sensitivity analyses were performed with respect to laminar flame speeds of CtLmixtures. The results are shown in Fig. 11. The main chain branching reaction $\mathrm{H}+\mathrm{O}_{2} \rightleftarrows \mathrm{OH}$ $+\mathrm{O}$ and the reaction governing heat release $\mathrm{CO}+\mathrm{OH} \rightleftarrows \mathrm{CO}_{2}+\mathrm{H}$ are most sensitive with respect to the flame speed, as expected. The sensitivity increases with increasing pressure. In addition, reactions of the H/O- and CO-sub-systems, reactions of the $\mathrm{C}_{2} \mathrm{H}_{\mathrm{x}}$ and $\mathrm{C}_{3} \mathrm{H}_{\mathrm{x}}$ species resulting from the combustion of large alkanes also show some sensitivity to the flame speed. The reactions involving higher hydrocarbons were found relatively insensitive.

\section{CONCLUSIONS}

For the first time, the kinetics of oxidation of a Coal-to-Liquid Fully Synthetic Jet Fuel (CtL-FSJF) was studied using three complementary laboratory experimental set-ups operating over a wide range of conditions: a JSR (at $p=10$ bar and a constant residence time of $1 \mathrm{~s}$, $770<T / \mathrm{K}<1070$, and for variable equivalence ratios $0.5<\varphi<2$ ), a shock-tube (at $p$ around 16 bar, $900<T / \mathrm{K}<1400, \varphi=0.5$ and $\varphi=1$ ), and a conical flame burner (preheat temperature $T_{0}$ 
$=473 \mathrm{~K}$, and for two pressure regimes: $p=1$ bar, $0.95<\varphi<1.40$ and $p=3$ bar, $0.95<\varphi<$ 1.3). In the JSR, concentration profiles of reactants, stable intermediates, and final products were obtained by probe sampling followed by on-line and off-line gas chromatography analyses and on-line Fourier Transformed Infra-Red spectrometry. Ignition delay times were measured behind reflected shock waves by recording time-dependent $\mathrm{CH}^{*}$ emission at 431 $\mathrm{nm}$. Flame speeds were determined by applying the cone angle method. These data were compared to corresponding results obtained for the oxidation, ignition and combustion of Jet A-1, showing strong similarity whereas some differences appeared, mainly in terms of intermediate products concentrations.

The oxidation of this CtL-jet fuel under these conditions was modeled using a detailed kinetic reaction mechanism and simple surrogate model fuel (n-decane, iso-octane, $n$ propylcyclohexane, and n-propylbenzene). A reasonable representation of the kinetics of oxidation of the jet fuel was obtained. Future modeling improvements could be achieved by using a more complex model fuel involving more realistic alkanes and naphthenes for which the kinetics has recently been proposed ${ }^{43-47}$.

Within the parameter range studied, the measured data of burning velocity and ignition delay time agree with data obtained earlier for petrol-derived kerosene. The information on the laminar flame speed can have some impact on the jet turbine burner design and the combustor as the flame will be stabilized at different heights above the burner depending on the flame length and therefore heat load of the walls or the recirculation zones may change. The knowledge on ignition delay times allows a better estimation of the risk of flashback or auto-ignition occurrence.

Our findings support the potential of the CtL mixture investigated to serve as an alternative aviation fuel. The results of the present study will contribute to optimizing synthetic jet fuel mixtures for practical combustors. 


\section{ASSOCIATED CONTENT}

\section{Supporting Information}

The proposed chemical kinetic reaction mechanism in CHEMKIN format, the associated thermochemical and transport data in CHEMKIN format. This material is available free of charge via the Internet at http://pubs.acs.org.

\section{ACKNOWLEDGEMENTS}

The authors thank N. Ackermann for his assistance in running the shock tube experiments and C. Wahl and M. Kapernaum for their analysis of the fuels compositions. This work was performed within the EU FP7 project ALFA-BIRD: EUFP7/2007-2013, grant agreement no. 213266. 


\section{Figure captions}

Figure 1. Determination of the burning velocity by applying the cone angle method ${ }^{26}$.

Figure 2. Typical pressure (upper trace) and derived temperature profile (lower trace) assuming adiabatic isentropic compression obtained for conditions of $T_{5 \mathrm{~s}}=929 \mathrm{~K}$ and $p_{5 \mathrm{~s}}=$ 15.30 bar.

Figure 3. CtL-FSJF oxidation in a JSR at $\varphi=0.5, p=10$ bar, and $t=1 \mathrm{~s}$ (Data: large symbols, simulations: lines and small symbols).

Figure 4. CtL-FSJF oxidation in a JSR at $\varphi=1.0, p=10$ bar, and $t=1 \mathrm{~s}$ (Data: large symbols, simulations: lines and small symbols).

Figure 5. CtL-FSJF oxidation in a JSR at $\varphi=2.0, p=10$ bar, and $t=1 \mathrm{~s}$ (Data: large symbols, simulations: lines and small symbols).

Figure 6. Comparison of experimental data obtained in a JSR for the oxidation of Jet A-1 (closed symbols) and CtL (open symbols) at $\varphi=1.0, p=10 \mathrm{bar}$, and $t=1 \mathrm{~s}$. The initial fuel concentration was $1000 \mathrm{ppm}$.

Figure 7. Ignition delay time: Comparison between measurements (solid circles: CtL-FSJF; open circles: CtL-FSJF surrogate, squares: Jet A-1) and predictions for CtL-FSJF / Jet A-1 surrogate - air mixtures diluted in $\mathrm{N}_{2}(1: 2)$ at $\varphi=0.5$ and $p=16$ bar.

Figure 8. Ignition delay time: Comparison between measurements (solid star: CtL-FSJF; open star: CtL-FSJF surrogate; squares: Jet A-1) and predictions for CtL / Jet A-1 surrogate - air mixtures diluted in $\mathrm{N}_{2}(1: 2)$ at $\varphi=1.0$ and $p=16$ bar.

Figure 9. Ignition delay time: Comparison between measurements (solid star: CtL-FSJF; open star: CtL-FSJF surrogate) and predictions for CtL-FSJF / CtL-FSJF surrogate - air mixtures diluted in $\mathrm{N}_{2}(1: 2)$ at $\varphi=1.0$ and $p=16$ bar. Ignition delay times calculated at constant 
pressure for pure $n$-decane, $n$-propylbenzene, $n$-propylcyclohexane, and iso-octane are also shown.

Figure 10. Comparison of measured burning velocity and predicted laminar flame speed of CtL-FSJF -air mixture (triangles) at $T_{0}=473 \mathrm{~K}$ and $p=1$ and 3 bar and Jet A-1 (diamond: present work; circles: Chong and Hochgreb ${ }^{12}$, squares: Vukadinovic et al. ${ }^{35}$ ) at $T_{0}=473 \mathrm{~K}$ and $p=1$ bar.

Figure 11. Sensitivity analysis of CtL-FSJF -air mixture with respect to laminar flame speed; results are shown for a stoichiometric mixture. 


\section{Figures}

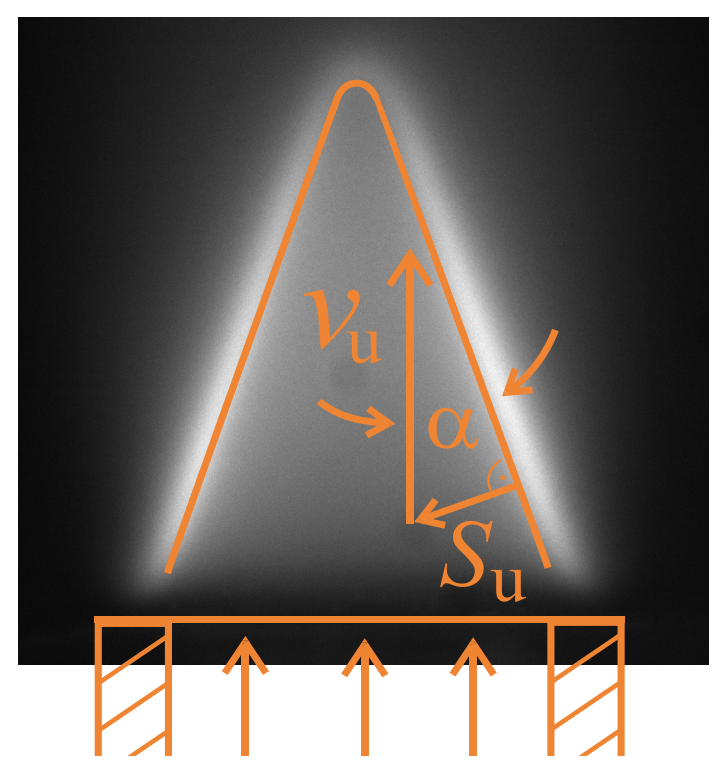

Figure 1. Determination of the burning velocity by applying the cone angle method ${ }^{26}$.

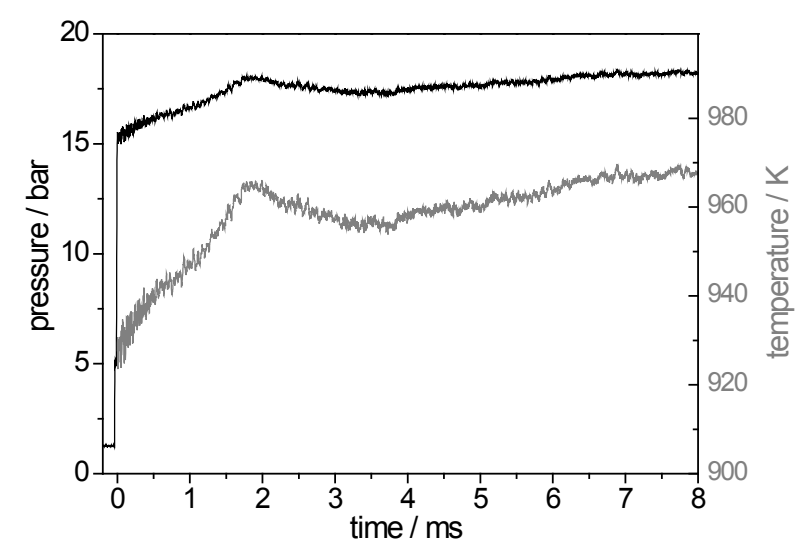

Figure 2. Typical pressure (upper trace) and derived temperature profile (lower trace) assuming adiabatic isentropic compression obtained for conditions of $T_{5 \mathrm{~s}}=929 \mathrm{~K}$ and $p_{5 \mathrm{~s}}=15.30 \mathrm{bar}$. 


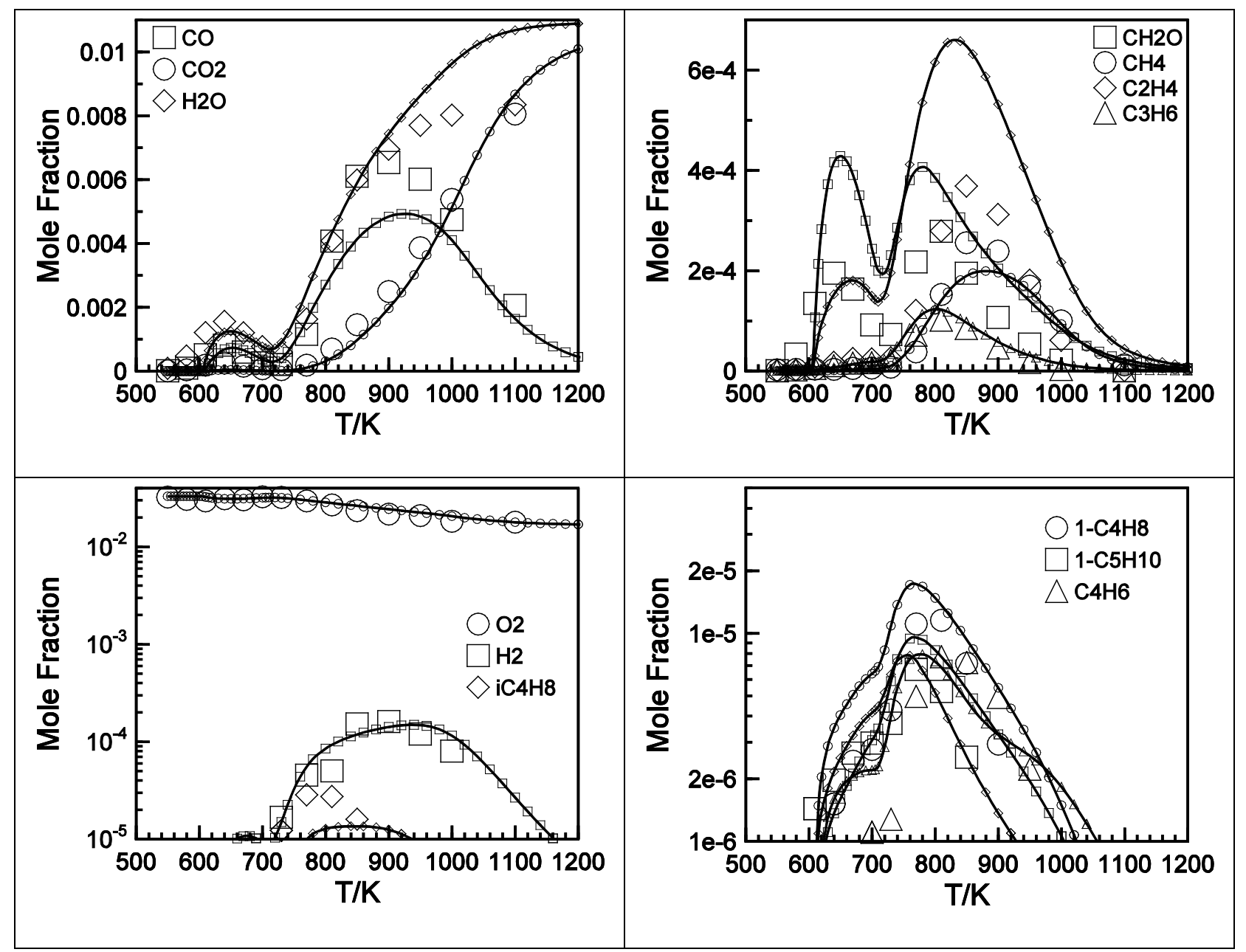

Figure 3. CtL-FSJF oxidation in a JSR at $\varphi=0.5, p=10$ bar, and $t=1 \mathrm{~s}$ (Data: large symbols, simulations: lines and small symbols). 


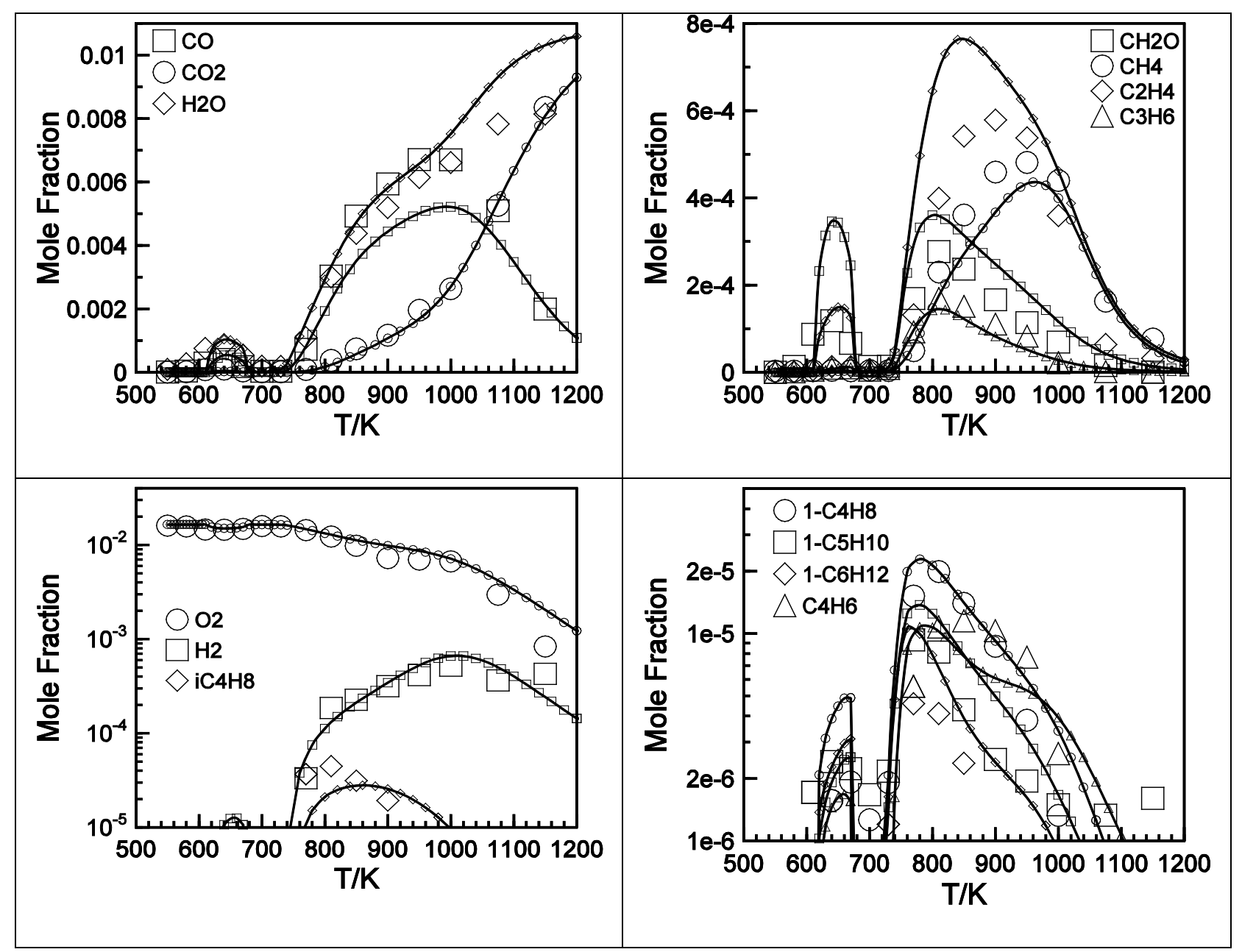

Figure 4. CtL-FSJF oxidation in a JSR at $\varphi=1.0, p=10$ bar, and $t=1 \mathrm{~s}$ (Data: large symbols, simulations: lines and small symbols). 


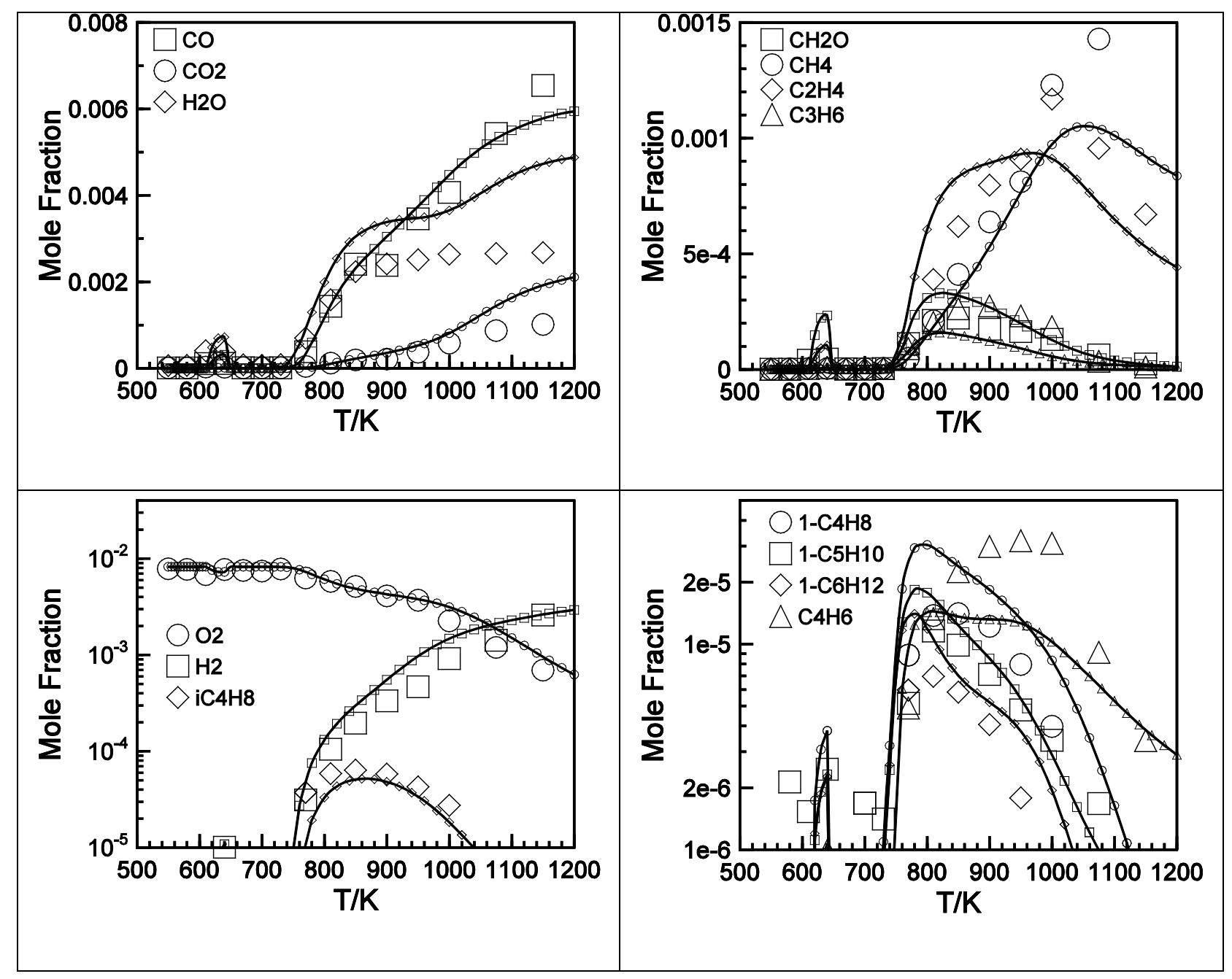

Figure 5. CtL-FSJF oxidation in a JSR at $\varphi=2.0, p=10$ bar, and $t=1 \mathrm{~s}$ (Data: large symbols, simulations: lines and small symbols). 

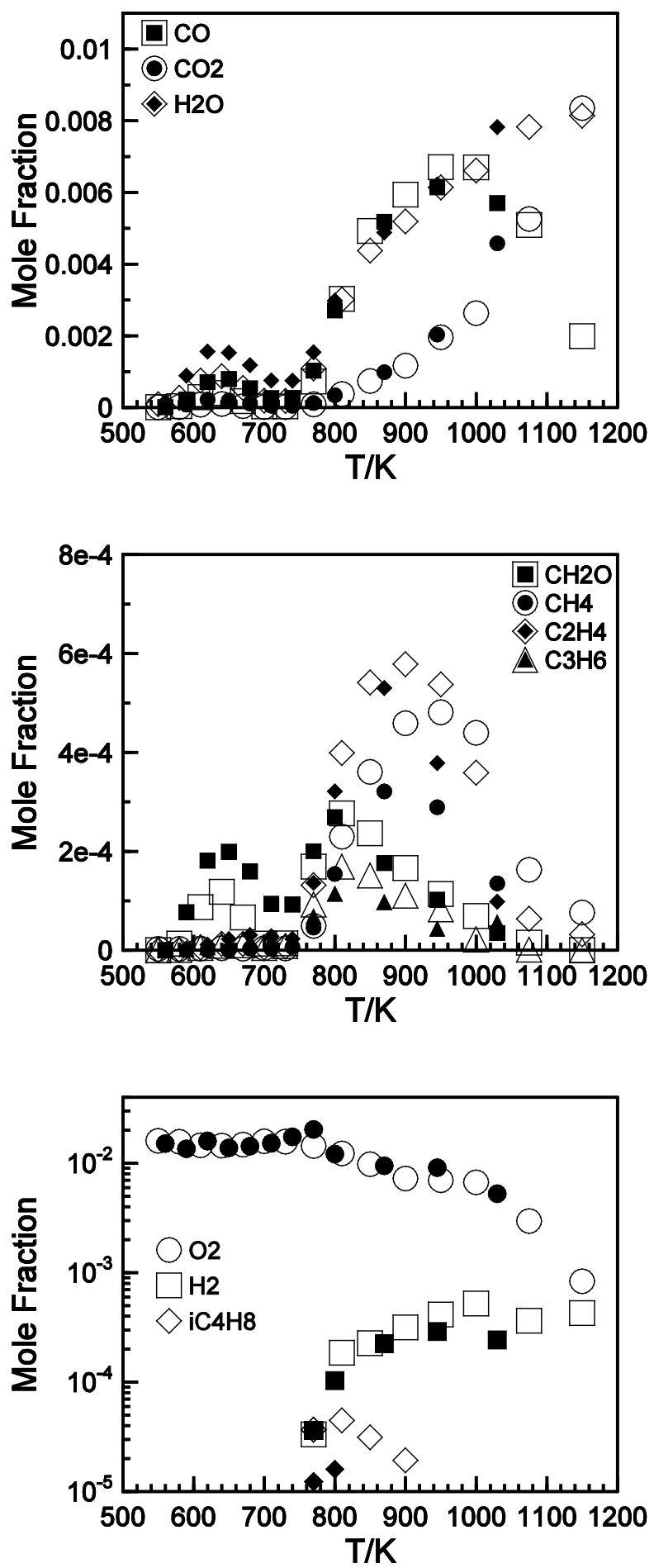

Figure 6. Comparison of experimental data obtained in a JSR for the oxidation of Jet A-1 (closed symbols) and CtL (open symbols) at $\varphi=1.0, p=10 \mathrm{bar}$, and $t=1 \mathrm{~s}$. The initial fuel concentration was $1000 \mathrm{ppm}$. 


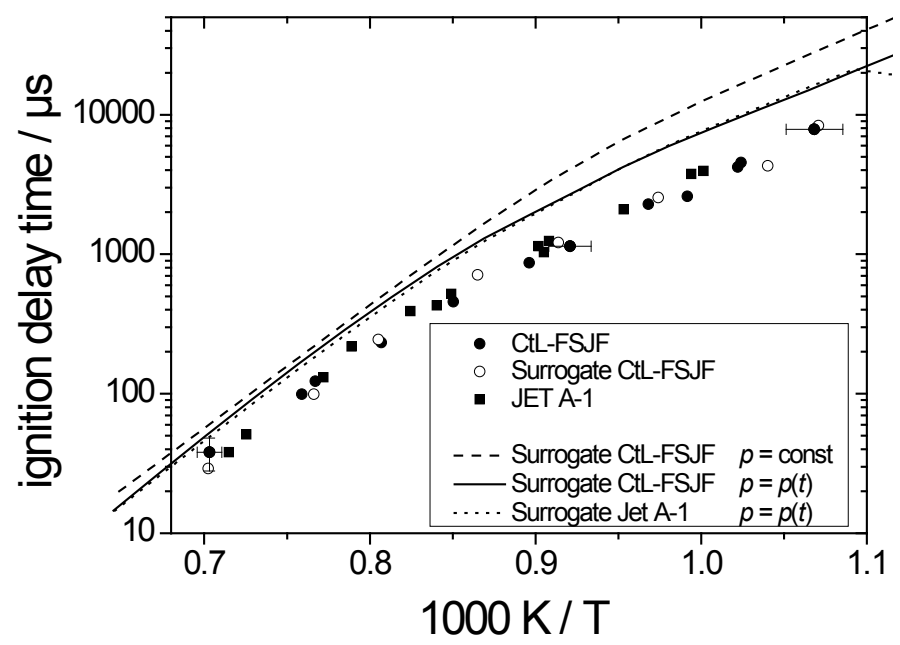

Figure 7. Ignition delay time: Comparison between measurements (solid circles: CtL-FSJF; open circles: CtL-FSJF surrogate, squares: Jet A-1) and predictions for CtL-FSJF / Jet A-1 surrogate - air mixtures diluted in $\mathrm{N}_{2}(1: 2)$ at $\varphi=0.5$ and $p=16$ bar.

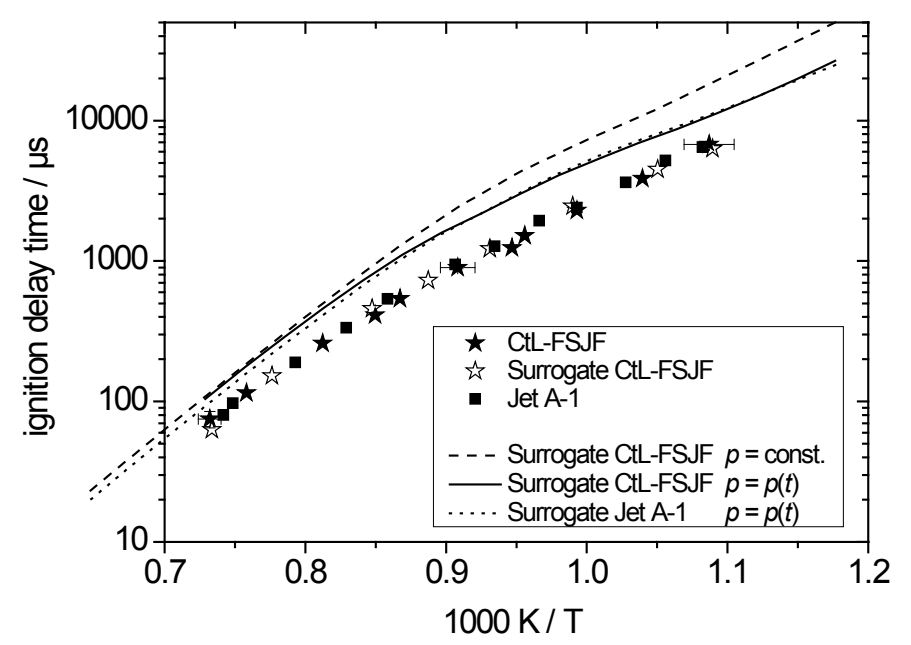

Figure 8. Ignition delay time: Comparison between measurements (solid star: CtL-FSJF; open star: CtL-FSJF surrogate; squares: Jet A-1) and predictions for CtL / Jet A-1 surrogate - air mixtures diluted in $\mathrm{N}_{2}(1: 2)$ at $\varphi=1.0$ and $p=16$ bar. 


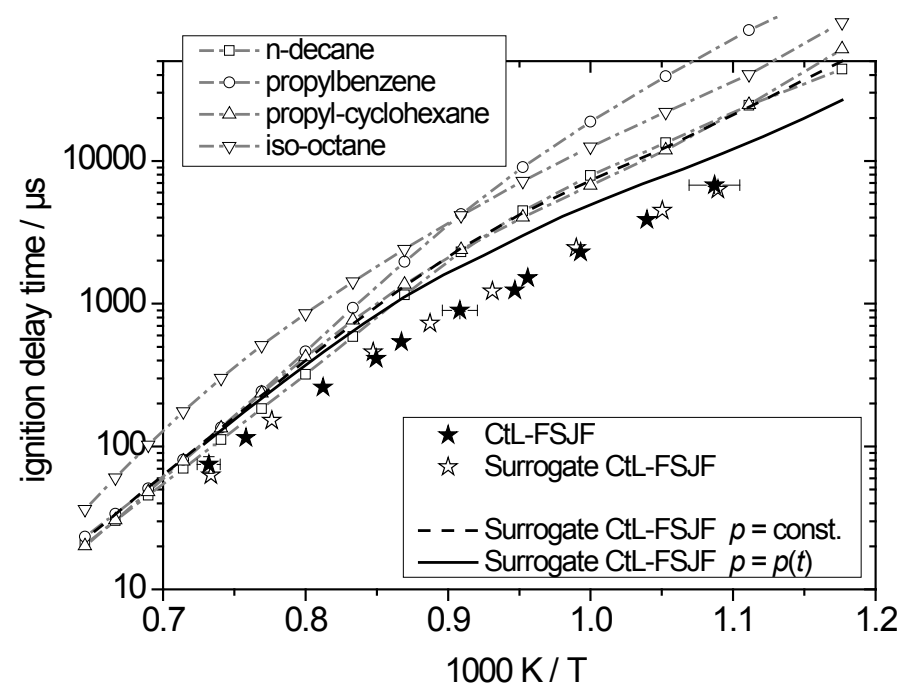

Figure 9. Ignition delay time: Comparison between measurements (solid star: CtL-FSJF; open star: CtL-FSJF surrogate) and predictions for CtL-FSJF / CtL-FSJF surrogate - air mixtures diluted in $\mathrm{N}_{2}(1: 2)$ at $\varphi=1.0$ and $p=16$ bar. Ignition delay times calculated at constant pressure for pure $n$-decane, $n$-propylbenzene, $n$-propylcyclohexane, and iso-octane are also shown.

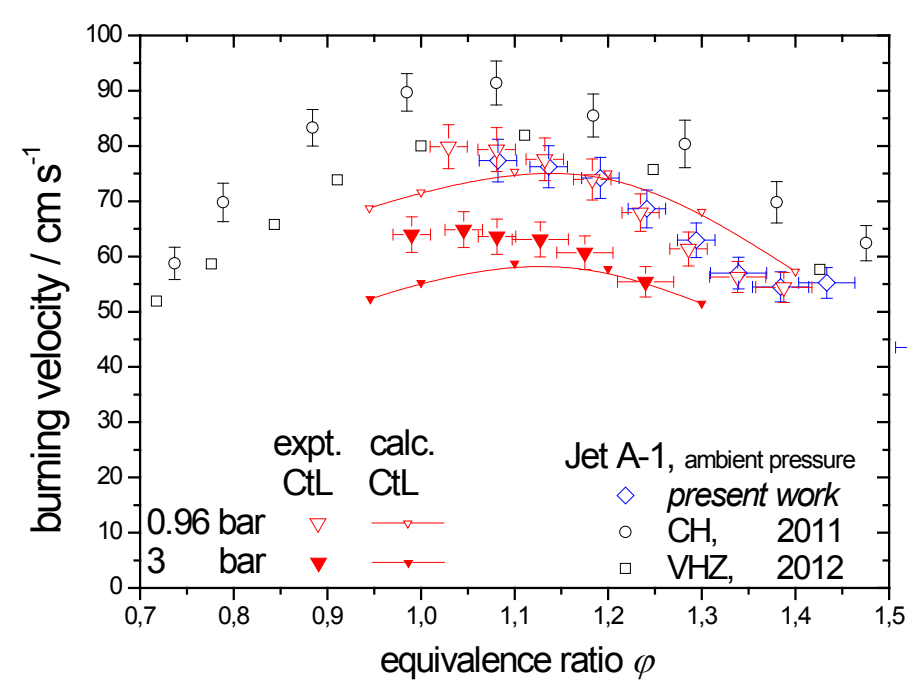

Figure 10. Comparison of measured burning velocity and predicted laminar flame speed of CtL-FSJF -air mixture (triangles) at $T_{0}=473 \mathrm{~K}$ and $p=1$ and 3 bar and Jet A-1 (diamond: present work; circles: Chong and Hochgreb ${ }^{12}$, squares: Vukadinovic et al. ${ }^{35}$ ) at $T_{0}=473 \mathrm{~K}$ and $p=1$ bar. 


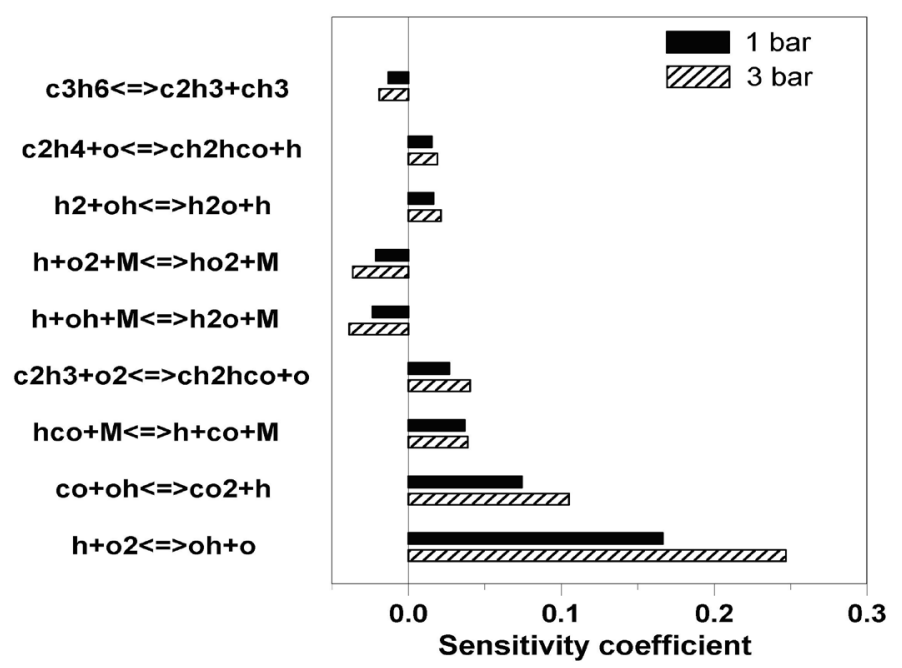

Figure 11. Sensitivity analysis of CtL-FSJF -air mixture with respect to laminar flame speed; results are shown for a stoichiometric mixture 


\section{REFERENCES}

1. European-Commission.

Biofuels

flight

path.

http://ec.europa.eu/energy/renewables/biofuels/doc/20110622 biofuels flight path technical paper.pdf.

2. Dagaut, P.; Cathonnet, M., The ignition, oxidation, and combustion of kerosene: A review of experimental and kinetic modeling. Prog. Energy Combust. Sci. 2006, 32, (1), 4892.

3. ASTM, Standard Specification for Aviation Turbine Fuels. In Standard Specification for Aviation Turbine Fuels, 2011; Vol. D1655.

4. Wahl, C.; Kapernaum, M. Computational fluid dynamics for combustion CFD4C, EU project G4RD-CT-1999-00075; 2000.

5. Steil, U.; Braun-Unkhoff, M.; Aigner, M. In 46th AIAA Aerospace Science Meeting AIAA-2008-0973, Reno, Nevada, USA, 7 - 10 Jan, 2008; Reno, Nevada, USA, 2008.

6. Eberius, H.; Kick, T., Stabilization of Premixed, Conical Methane Flames at High Pressure. Ber Bunsen Ges Phys Chem 1992, 96, (10), 1416-1419.

7. Braun-Unkhoff, M.; Slavinskaya, N.; Aigner, M. In ASME Turbo Expo, Glasgow, UK, June 14-18, 2010; ASME: Glasgow, UK, 2010; pp GT2010-23360.

8. Vagelopoulos, C. M.; Egolfopoulos, F. N., Laminar flame speeds and extinction strain rates of mixtures of carbon monoxide with hydrogen, methane, and air. Symposium (International) on Combustion 1994, 25, (1), 1317-1323.

9. McLean, I. C.; Smith, D. B.; Taylor, S. C., The use of carbon monoxide/hydrogen burning velocities to examine the rate of the $\mathrm{CO}+\mathrm{OH}$ reaction. Symposium (International) on Combustion 1994, 25, (1), 749-757.

10. Skjoth-Rasmussen, M. S.; Braun-Unkhoff, M.; Naumann, C.; Frank, P. In paper 012.2003, 3rd European conference Meeting, Orléans, France, October 25-28, 2003; Orléans, France, 2003.

11. Ji, C. S.; Wang, Y. L.; Egolfopoulos, F. N., Flame Studies of Conventional and Alternative Jet Fuels. J. Propul. Power 2011, 27, (4), 856-863.

12. Chong, C. T.; Hochgreb, S., Measurements of laminar flame speeds of liquid fuels: Jet-A1, diesel, palm methyl esters and blends using particle imaging velocimetry (PIV). Proc. Combust. Inst. 2011, 33, (1), 979-986.

13. Ji, C.; Dames, E.; Sirjean, B.; Wang, H.; Egolfopoulos, F. N., An experimental and modeling study of the propagation of cyclohexane and mono-alkylated cyclohexane flames. Proc. Combust. Inst. 2011, 33, (1), 971-978. 
14. Ji, C.; Egolfopoulos, F. N., Flame propagation of mixtures of air with binary liquid fuel mixtures. Proc. Combust. Inst. 2011, 33, (1), 955-961.

15. Vukadinovic, V.; Habisreuther, P.; Zarzalis, N. In ASME Turbo Expo, Glasgow, UK, June 14-18, 2010; ASME: Glasgow, UK, 2010; pp 441-450.

16. Kick, T.; Kathrotia, T.; Braun-Unkhoff, M.; Riedel, U. In ASME Turbo Expo, Vancouver, Canada, June 6-10, 2011; Vancouver, Canada, 2011; pp GT2011-45606.

17. Mze-Ahmed, A.; Hadj-Ali, K.; Dievart, P.; Dagaut, P., Kinetics of Oxidation of a Synthetic Jet Fuel in a Jet-Stirred Reactor: Experimental and Modeling Study. Energy Fuels 2010, 24, 4904-4911.

18. ALFA-BIRD Alternative fuels and biofuels for aircraft development, EU FP7 project: EUFP7/2007-2013, Grant agreement 213266; 2007.

19. SWAFEA Sustainable way for alternative fuels and energy for aviation, EU, 2012.

20. Naik, C. V.; Puduppakkam, K. V.; Modak, A.; Meeks, E.; Wang, Y. L.; Feng, Q. Y.; Tsotsis, T. T., Detailed chemical kinetic mechanism for surrogates of alternative jet fuels. Combust. Flame 2011, 158, (3), 434-445.

21. Dooley, S.; Won, S. H.; Chaos, M.; Heyne, J.; Ju, Y. G.; Dryer, F. L.; Kumar, K.; Sung, C. J.; Wang, H. W.; Oehlschlaeger, M. A.; Santoro, R. J.; Litzinger, T. A., A jet fuel surrogate formulated by real fuel properties. Combust. Flame 2010, 157, (12), 2333-2339.

22. Dagaut, P.; Cathonnet, M.; Rouan, J. P.; Foulatier, R.; Quilgars, A.; Boettner, J. C.; Gaillard, F.; James, H., A Jet-Stirred Reactor for Kinetic-Studies of Homogeneous Gas-Phase Reactions at Pressures up to 10-Atmospheres ( $1 \mathrm{MPa})$. Journal of Physics E-Scientific Instruments 1986, 19, (3), 207-209.

23. Dagaut, P., Kinetics of jet fuel combustion over extended conditions: Experimental and modeling. J. Eng. Gas Turbines Power-Transact. of the Asme 2007, 129, (2), 394-403.

24. Dagaut, P.; El Bakali, A.; Ristori, A., The combustion of kerosene: Experimental results and kinetic modelling using 1- to 3-component surrogate model fuels. Fuel 2006, 85, (7-8), 944-956.

25. Herzler, J.; Jerig, L.; Roth, P., Shock tube study of the ignition of lean n-heptane/air mixtures at intermediate temperatures and high pressures. Proc. Combust. Inst. 2005, 30, (1), 1147-1153.

26. Andrews, G. E.; Bradley, D., Determination of burning velocities: A critical review. Combust. Flame 1972, 18, (1), 133-153.

27. Braun-Unkhoff, M.; Kick, T.; Frank, P.; Aigner, M. In ASME Turbo Expo, Montréal, Canada, May 14-17, 2007; ASME: Montréal, Canada, 2007; pp GT2007-27479. 
28. Aschenbrenner, H.; Nieken, U. Institut für Chemische Verfahrenstechnik (ICVT), Univertity Stuttgart, Germany; 2007.

29. Kick, T.; Herbst, J.; Kathrotia, T.; Marquetand, J.; Braun-Unkhoff, M.; Naumann, C.; Riedel, U., An experimental and modeling study of burning velocities of possible future synthetic jet fuels. Energy 2012, 43, (1), 111-123.

30. Edwards, T.; Atria, J. V. In Thermal Stability of High Temperature Fuels, ASME Turbo Expo, Orlando, Florida, USA, June 2-5, 1997; ASME: Orlando, Florida, USA, 1997; pp GT1997-143.

31. Law, C. K., Dynamics of stretched flames. Symposium (International) on Combustion 1989, 22, (1), 1381-1402.

32. Rallis, C. J.; Garforth, A. M., The determination of laminar burning velocity. Prog. Energy Combust. Sci. 1980, 6, (4), 303-329.

33. Wu, C. K.; Law, C. K., On the determination of laminar flame speeds from stretched flames. Symposium (International) on Combustion 1985, 20, (1), 1941-1949.

34. Markstein, G. H., Non-Steady Flame Propagation. Pergamon: New York (USA), 1964.

35. Vukadinovic, V.; Habisreuther, P.; Zarzalis , N. In Experimental study on combustion characteristics of conventional and alternative liquid fuels, ASME Turbo Expo, Copenhagen, Denmark June 11-15, 2012; ASME: Copenhagen, Denmark 2012; pp GT2012-69449.

36. Kee, R. J.; Rupley, F. M.; Miller, J. A. The Chemkin Thermodynamic Data Base; SAND87-8215; Sandia National Laboratories: Livermore, CA, 1987.

37. Kee, R. J.; Rupley, F. M.; Miller, J. A. CHEMKIN-II: A Fortran Chemical Kinetics Package for the Analysis of Gas-Phase Chemical Kinetics.; SAND89-8009; Sandia National Laboratories: Livermore, CA, 1989.

38. Glarborg, P.; Kee, R. J.; Grcar, J. F.; Miller, J. A. PSR: A FORTRAN program for modeling well-stirred reactors; SAND86-8209; Sandia National Laboratories: Livermore, CA, 1986.

39. Herzler, J.; Naumann, C., Shock-tube study of the ignition of methane/ethane/hydrogen mixtures with hydrogen contents from $0 \%$ to $100 \%$ at different pressures. Proc. Combust. Inst. 2009, 32, (1), 213-220.

40. Kee, R. J.; J.F., G.; M.D., S.; Miller, J. A. A Fortran program for modeling steady laminar one-dimensional premixed flames.; SAND85-8240; Sandia National Laboratories: Livermore, CA, 1985. 
41. Lutz, A. E.; Kee, R. J.; Miller, J. A. Senkin: A Fortran program for predicting homogeneous gas phase chemical kinetics with sensitivity analysis; Sandia National Laboratories: Livermore, CA, 1987.

42. Dagaut, P.; Gail, S., Chemical kinetic study of the effect of a biofuel additive on JetA1 combustion. J. Phys. Chem. A 2007, 111, (19), 3992-4000.

43. Sarathy, S. M.; Westbrook, C. K.; Mehl, M.; Pitz, W. J.; Togbe, C.; Dagaut, P.; Wang, H.; Oehlschlaeger, M. A.; Niemann, U.; Seshadri, K.; Veloo, P. S.; Ji, C.; Egolfopoulos, F.; $\mathrm{Lu}, \mathrm{T}$., Comprehensive chemical kinetic modeling of the oxidation of $\mathrm{C} 8$ and larger n-alkanes and 2-methylalkanes. Combust. Flame 2011, 158 (12), 2338-2357

44. Sarathy, S. M.; Westbrook, C. K.; Mehl, M.; Pitz, W. J.; Togbe, C.; Dagaut, P.; Wang, H.; Oehlschlaeger, M. A.; Niemann, U.; Seshadri, K.; Veloo, P. S.; Ji, C.; Egolfopoulos, F. N.; Lu, T., Comprehensive chemical kinetic modeling of the oxidation of 2-methylalkanes from C(7) to C(20). Combust. Flame 2011, 158, (12), 2338-2357.

45. Mze-Ahmed, A.; Hadj-Ali, K.; Dagaut, P.; Dayma, G., Experimental and Modeling Study of the Oxidation Kinetics of n-Undecane and n-Dodecane in a Jet-Stirred Reactor. Energy Fuels 2012, 26, (7), 4253-4268.

46. Karsenty, F.; Sarathy, S. M.; Togbé, C.; Westbrook, C. K.; Dayma, G.; Dagaut, P.; Mehl, M.; Pitz, W. J., Experimental and Kinetic Modeling Study of 3-Methylheptane in a JetStirred Reactor. Energy Fuels 2012, 26, (8), 4680-4689.

47. Dagaut, P.; Ristori, A.; Frassoldati, A.; Faravelli, T.; Dayma, G.; Ranzi, E., Experimental and semi-detailed kinetic modeling study of decalin oxidation and pyrolysis over a wide range of conditions. Proc. Combust. Inst. 2013, 34, (1), doi: 10.1016/j.proci.2012.05.099. 